\title{
In Search of the Optimal Saving Strategy for Pan-European Pension Products
}

\author{
Ján Šebo ${ }^{1}$, Daniela Danková2 ${ }^{2}$ Ivan Králik ${ }^{3}$ \\ ${ }^{1}$ Matej Bel University \\ Faculty of Economics, Department of Public Economics \\ Tajovského 10, Banská Bystrica, Slovakia \\ E-mail: jan.sebo@umb.sk \\ 2 Matej Bel University \\ Faculty of Economics, Department of Public Economics \\ Tajovského 10, Banská Bystrica, Slovakia \\ E-mail: daniela.dankova@umb.sk \\ 3 Matej Bel University \\ Faculty of Economics, Department of Public Economics \\ Tajovského 10, Banská Bystrica, Slovakia \\ E-mail: ivan.kralik@umb.sk
}

\begin{abstract}
The introduction of pan-European pension products in 2020 is associated with an ongoing debate on prescribing predefined saving strategy that would both deliver adequate performance and limit the down-side risk at the end of the saving horizon. Dynamic life-cycle saving strategies are generally accepted as a good riskmitigation tool that can be individually set. Many research papers confirm the ability of life-cycle strategies to deliver high risk-reward outcomes. Objective of our paper is to test the ability of one-factor life-cycle saving strategies based on the age and/or the remaining saving horizon to deliver the promised value for PEPP savers. We constructed 18 saving strategies divided into three groups - static saving strategies with fixed proportion of equities, dynamic life-cycle strategies based on the age and/or remaining saving horizon, and quasi-active strategies combining two factors - the remaining saving horizon and price movement. We employed the model based on moving-block bootstrapping technique and performed simulations for various economic conditions. We have tested the expected saving performance combined with the down-side risk during the saving horizon. Our findings do not confirm the general findings on life-cycle saving strategies. We claim that having the age as the only factor defining the proportion of equities in the pension saving portfolio would not be optimal. However, we found that two-factor saving strategies look promising in delivering both lower down-side risk and higher performance over the saving horizon.
\end{abstract}

Keywords: pan-European pension product, savings performance, life-cycle strategy, quasi-active saving strategy, down-side risk

JEL codes: $G 11, G 17, G 18, G 51$ 


\section{Introduction}

Several years of EU-wide discussion on bringing a portable pension product to the market has led to the creation of pan-European pension product (PEPP) regulation that inter alia enables the creation of a personal pension product which will have a long-term retirement nature and will take into account environmental, social and governance (ESG) factors, will be simple, safe, reasonably-priced, transparent, consumer-friendly and portable and will complement the existing pension systems in all EU member states.

A PEPP is an individual non-occupational pension product subscribed to voluntarily by a PEPP saver in view of retirement. Because a PEPP should provide for long-term capital accumulation, possibilities for the early withdrawal of capital should be limited and might be penalized. One of the objectives of regulating PEPPs is to create a safe, cost-friendly long-term retirement savings product. Because the investments concerning personal pension products are long-term, special regard should be given to the long-term consequences of asset allocation. For this sake, the predefined option of simple PEPP includes pure gradual investment process that should ensure adequate returns over the long-term.

As the PEPP market should cover the entire EU, the regulation includes requirements to provide potential savers with information on the investment options including the risk mitigation techniques. At the same time, the recommendation to the member states asks to treat the PEPP product the same way the national personal products are treated from the taxation point of view.

However, granting the tax benefits to a relatively new pension saving product, where the outcomes are uncertain, leads to an ongoing debate on searching for a predefined investment option based on expected pension outcomes. A vast amount of research have focused on optimal saving strategies under various constraints. However, finding a comparative analysis of simple passive and quasi-active saving strategies using robust simulation techniques is rather difficult. We try to complement the discussion on searching for an optimal predefined saving strategy for PEPP with the comparison of several quasi active, passive and life-cycle strategies using a complex stochastic microsimulation process.

\section{Literature Review}

Discussions on the optimal life-cycle gradual saving process are unstoppable and gain on interest under the capital markets union discussion that brings into the reality the new EU-wide long-term saving product - the PEPP. National regulators are discussing the optimal predefined investment strategy for simple capital accumulating process, which spurs the research further. When inspecting the existing research, generally, we can say that the goal of life-cycle portfolio allocation problems is to determine the optimal consumption and investment choices of an investor with total wealth consisting of human capital, financial wealth and other real assets, such as housing property. Without devoting much space to the introduction of the life-cycle investment strategy concept, we rather refer to 
seminal papers of Samuelson (1969) or Merton (1972), which perfectly present key aspects of building optimal life-cycle portfolios under various constraints. There is an increasing international consensus that life cycle strategies with a high portion of equities at the start and a decreasing portion towards retirement are desirable when managing the pension accumulation phase. However, although researchers agree that a life-cycle default pension program with decreasing risk towards retirement is desirable, the actual portfolio allocation and the strategies to be implemented are still under debate (Antolin et al., 2010).

Berstein et al. (2013) presented research regarding investment strategies for Chile to examine differences in contributors' profiles. They ran simulations of the replacement rate probability function 10,000 times and measured the median replacement rate versus the standard deviation for risk measurement. Even if they found no dominant strategy, they found that a 1 percent increase in risk leads to a gain of 0,85 points in the replacement rate.

Manor (2017) analyzed defined contribution pension schemes in Israel. The conclusion from his research is that life-cycle dynamic investment strategies are superior to static fixed strategies and to linear strategies. The strategies that lay on the efficient frontier had a high portion of equities at the starting point, which was gradually reduced every 5 or 10 years, or kept the same portion of equities for 20 years, and then gradually reduced it until no equities were left in the portfolio at retirement. The second conclusion is that a high portion of equities during the accumulation phase is essential for achieving high returns and high replacement rates. On the other hand, in the last period of the work phase, the portion of equities must be minimized to reduce the high risk of losing the accumulation. Another important conclusion is that the static investment policy, which is commonly used in Israel, with fixed $30-35 \%$ equities, should be changed to a dynamic, life-cycle strategy that can produce significantly higher replacement rates than the statically fixed strategy with a slightly higher risk.

His approach but using the more appropriate moving block bootstrapping technique has been followed by Fodor and Cenker (2019), who studied various life-cycle saving strategies applicable for the 1 bis pension pillar in Slovakia. Comparing expected returns for a given level of risk measured by $\mathrm{VaR}$, or CVaR, they concluded that the optimal strategy should invest into the riskier equity-based portfolios at the beginning of the saving horizon and only gradually switch into bonds later in the career. However, they found that even at the moment of retirement, the equities should be present in the pension portfolios.

Berardi et al. (2018) tested various "predefined" investment options for long-term savings products using Monte Carlo simulation and concluded that life-cycle strategies allow savers to recoup the capital invested with a probability well above $99 \%$. Even though this probability will decline over a shorter savings period, it remains greater than $99 \%$ for a 20 -year accumulation period, indicating that lifecycling continues to provide robust downside protection even under shorter accumulation periods. 
The latest attempt to inspect applicable saving strategies has been performed directly by the EIOPA (2020), which should oversight and regulate pan-European pension products directly. The study inspected 64 saving strategies in total; out of which 14 strategies were solely based on the factor of age; while additional 11 strategies worked with the factors of age, risk aversion and level of savings. Additional 11 strategies followed the fixed allocation profile from $0 \%$ up to $100 \%$ in equities. The EIOPA (2020) study concluded that life-cycle strategies based solely on the factor of age are poorly performing and that under the saving principle, one needs to be more aggressively invested into equity portfolios.

When inspecting the optimal investment-based saving strategy, most of the papers use similar metrics for measuring the expected benefits as well as risks. For measuring benefits, replacement rates are often used. However, using this concept is strongly dependent on the input parameters of wage increase, probability of unemployment over the career and other market risks. Most of the studies, however, try to unify the approach by selecting the 40 -years saving horizon and following the concave shaped income function. In many cases, various representative agents are used if the redistributional effects are to be emphasized. For measuring the expected benefits, almost all studies try to present the returns on paid contributions that allow for a wider comparison of results. Risk measure, on the other hand, is usually measured using typical VaR approach (on the $95^{\text {th }}$ percentile) or CVaR approach if the fat tails of the return distribution should be considered. In some cases, we could find the maximum draw-down metrics that shows the worst-case scenario or the $100^{\text {th }}$ percentile of all down movements in the value of savings over time. This approach looks very interesting considering the behavioral pattern, where a saver faces the market risks over the saving horizon and must be able to sustain the risk and continue with the defined saving strategy.

\section{Methodology and Data}

The objective of our research is to test 18 saving strategies that would be considered simple and cost-efficient under the existing PEPP regulation. We try to provide the answers on whether applying simple life-cycle strategies considered as passive and based solely on the age and/or remaining saving horizon of a saver would generate adequate risk-reward results that can be generally accepted for the "predefined" option. In order to do that, we have applied stochastic microsimulation technique based on moving-block bootstrapping in order to allow for autocorrelation either in mean or variance present in time series data. Our approach follows the Fodor and Center (2019) approach; however, the length of the blocks is not fixed as in their case, but the blocks of data series are defined based on the economic cycle.

We use the moving-block bootstrap (resampling) method, which allows to increase the number of simulations by pseudo-randomly generated macroeconomic scenarios while preserving correlations among macroeconomic indicators $\left(k_{k}\right)$. Data on monthly macroeconomic indicators for the period of 1919 until 2017 include 
unemployment, inflation, GDP change, labor productivity, DJIA30 total returns and 3-7-year bonds with constant maturity returns. The empirical time series of macroeconomic variables $\left(\Delta k_{j ; t}\right)$ contain 1164 monthly values. Since we want to obtain monthly changes for each macroeconomic variable, in total we have 1163 monthly changes $\left(\Delta k_{j ; t}\right)$, where $t \in 1 ; 2 ; \ldots . . ; 1163$.

Next, we cut the empirical time-series into up-trending $\left(U p^{i}\right)$ and down-trending periods (Down ${ }^{i}$ ) using data from the NBER (2019) on economic cycles and mark each period with the appropriate index value $(i)$. Altogether, we have 18 uptrending and 18 down-trending periods. Figure 1 illustrates up-trending and downtrending economic periods between 1919 and 2017.

Figure 13 Up-trending and Down-trending Macroeconomic Periods in the US (1919-2017)

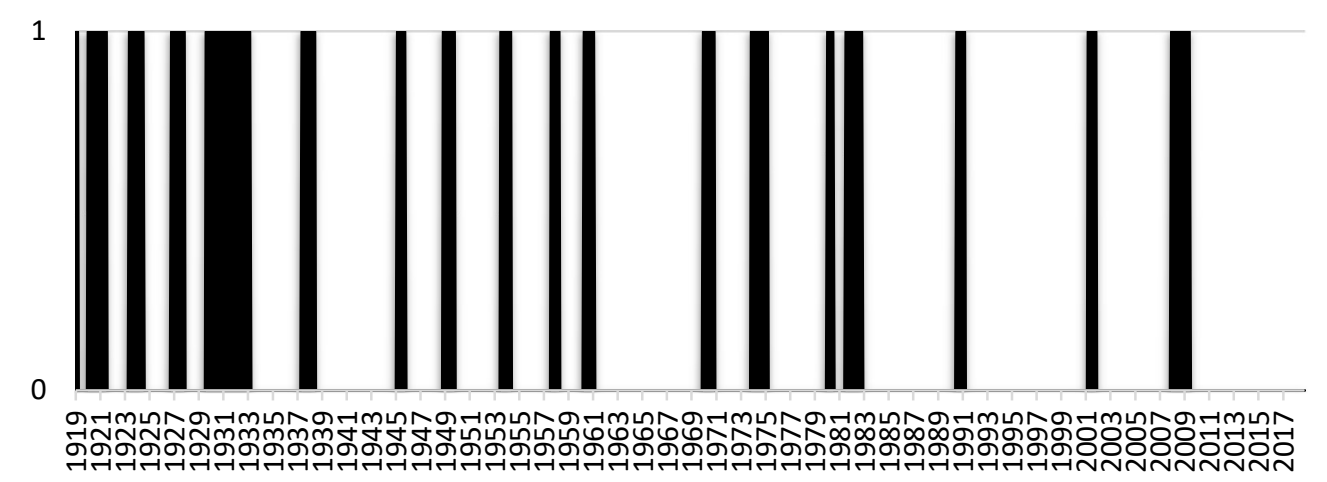

Source: NBER (2019), available at: http://www.nber.org/cycles/cyclesmain.html

*Note: Dark-colored columns represent the periods of economic downturn (recession).

Each period (i) has a precisely identified time series of macroeconomic variables $(\Delta k)$. Let us define a vector of time series of monthly changes in macroeconomic variables $\left(\Delta k_{k ; t}\right)$, where the lower index $k$ represents the observed macroeconomic variable (in a range of 1 to $K$ variables). Let us call the generated vector as a simulation block $\left(\boldsymbol{r}_{N}\right)$. The first simulation block $\left(\boldsymbol{r}_{\mathbf{1}}\right)$, which consist of empirically measured values of monthly changes in observed macroeconomic variables $\left(\Delta k_{k ; t}\right)$ and contains all up-trending and down-trending periods in a sequential order from 1 up to 18 , has the following form:

$$
\boldsymbol{r}_{\mathbf{1}}=\left[\begin{array}{ccc}
\Delta k_{1 ; 1} & \cdots & \Delta k_{1 ; 1163} \\
\vdots & \ddots & \vdots \\
\Delta k_{K ; 1} & \cdots & \Delta k_{K ; 1163}
\end{array}\right]
$$

In order to increase the number of simulations, we have created new simulation blocks using a resampling procedure. We combined up-trending and down-trending periods without repetition while maintaining the rule that each period (i) can only 
occur once. Applying the resampling technique, we have got a total of 150 simulation blocks $r_{N}$, where $N \in(1 ; \ldots ; 150)$.

Let us have a saver who buys an investment-based PEPP offering various saving strategies built on mixing the portfolio consisting of only two passively managed ETFs - equity and bond. Let the ETFs have the same net (after fees) performance as the US equity index DJIA30 and 7-10 years government bonds (for more details on the data structure, we refer to the previous chapter, where we used the same data for estimating expected returns). The agent buys a PEPP product at an age of 25 and decides to contribute $6 \%$ of their salary $(c(y))$ monthly for a 40 -year period. During their entire career they follow the life-cycle income path $\left(y_{h, t}^{i}\right)$ for a secondary education level including the labor market risk (unemployment) as referred by Fodor and Cenker (2019). Contributions $\left(C_{j, t}\right)$ based on the agent's salary can be defined as follows:

$$
C(y)_{t}=y_{h, t}^{i} * c(y)_{t}
$$

The value of savings $\left(S_{i j, T}\right)$ at the end of the saving period for specific saving strategy (a) can be calculated as follows (Kopa et al., 2019):

$$
S_{a j, T=} \sum_{t=1}^{T} C_{j, t}\left(1+\left(r_{s, t}^{*} * w_{a s, t}+r_{b, t}^{*} * w_{a b, t}\right)\right)^{T-t+1}
$$

We assume that new contributions $C(y)_{t}$ are invested at the beginning of each saving period $(t)$. It means that the first contribution is invested for a period of 480 months, the second contribution is invested for 479 months, and the last one is invested for 1 month only. When choosing the saving strategy, the respective agent can only change the allocation ratio once a year.

Finally, we can expose the agent to the randomness of external macroeconomic development. The simulation at the level of a specific age and educational cohort is performed as follows. For each simulation block $\left(\boldsymbol{r}_{N}\right)$, we start from the first month $(t=0)$ with the empirically gathered data on wages and respective unemployment rates for each age and educational cohort from the Statistical Office of Slovak Republic for the year 2016. Each month the values of the macroeconomic indicators change, which affects the individual status parameters of an economic agent.

We test three groups of saving strategies inspired by Šebo et al. (2017):

1. 11 static strategies with a fixed proportion of equities and bonds during the entire saving period;

2. 4 dynamic life-cycle strategies with linear decrease/increase in equities over the saving period based on the age and/or the remaining saving horizon of an agent;

3. 3 quasi active life-cycle strategies where the technical price action as well as the remaining saving horizon are considered. 
Most of the research papers promote simple dynamic life-cycle strategies, where either linear or logarithmic coefficient of equity proportion is considered. We claim that such strategies cannot be considered optimal as the market risk is not considered. Therefore, within the group of quasi active life-cycle strategies, we present two strategies that consider both the remaining saving horizon as well as market developments. The following parts of the chapter present the saving strategies in greater details.

Static strategies invest a constant proportion of savings into the equity ETF and do not take into account the remaining saving horizon of an agent or price movements. In total, we have constructed 11 strategies as presented in the table below.

Table 4 Allocation Profile of Static Passive Saving Strategies

\begin{tabular}{ccc}
\hline Saving strategy & $\begin{array}{c}\text { Proportion of savings in } \\
\text { the Equity ETF (in \%) }\end{array}$ & $\begin{array}{c}\text { Proportion of savings in } \\
\text { the Bond ETF (in \%) }\end{array}$ \\
\hline \hline Aggressive (only equities) & 100 & 0 \\
\hline $90: 10$ & 90 & 20 \\
\hline $80: 20$ & 80 & 30 \\
\hline $70: 30$ & 70 & 40 \\
\hline $60: 40$ & 60 & 50 \\
\hline $50: 50$ & 50 & 60 \\
\hline $40: 60$ & 40 & 70 \\
\hline $30: 70$ & 30 & 80 \\
\hline $20: 80$ & 20 & 90 \\
\hline $10: 90$ & 10 & 100 \\
\hline Conservative (only bonds) & 0 & \\
\hline
\end{tabular}

Source: Authors' own elaboration, 2019

The second group of saving strategies consists of four dynamic life-cycle strategies where the proportion of equities is solely dependent on the age and/or the remaining saving horizon of an agent. Typical life-cycle saving strategies are the Poterba style old-age scheme allocation strategies (Poterba et al., 2006), where the glide path is followed based on prescribed rules. Typically, the exposure to the riskier assets should decrease with the age. In order to account for this glide path, we constructed two typical life-cycle strategies that consider only the age of a saver and ignore the price movement of underlying assets over time. To complement these typical life-cycle strategies, we turned the logic upside down and constructed two inverse life-cycle strategies in order to see whether the key logic of the glide path is valid. In total, we present 4 life-cycle strategies based on the age of an agent.

The first life-cycle strategy called Aging 1 is based on the well-known rule of thumb, where the allocation weight $\left(w_{i s, t}\right)$ into the riskier equity ETF is based on the rule 
"100 - age" and the remaining portion $\left(1-w_{i s, t}\right)$ of the savings is allocated into the bond ETF. The rule can be defined as follows:

$$
w s ; \text { tAging } 1=100-x t \quad w_{s ; t}^{\text {Aging } 1}=100-x_{t}
$$

Where:

$w_{s ; t}^{A g i n g}$ represents a portion of savings allocated into the equity ETF;

$x$ represents the age of an economic agent (saver/investor) at time $t$, while $t \in$ $\langle 1, T\rangle$, where $T$ is the total saving horizon in years.

Aging2 strategy is a slightly modified version of the previous strategy and reduces the proportion of savings invested into the equity ETF relatively to the ratio of the number of years $t$ a saver has already saved to the years of the total saving horizon $(T)$ :

$$
w_{s ; t}^{\text {Aging } 2}=\left(1-\frac{t}{T}\right) \times 100
$$

Comparing to Aging1, Aging2 strategy allocates a higher proportion of saving into the equity ETF at the beginning of the saving horizon, but the decrease rate is steeper.

The remaining two aging strategies are inverse in their logic. The Aging3 strategy increases the exposure to the equities with the rising age:

$$
w_{s ; t}^{\text {Aging } 3}=x_{t}
$$

Aging4 strategy increases the exposure to the equity ETF base on the ratio of the number of years $t$ a saver has already saved to the years of the total saving horizon $(T)$ :

$$
w_{s ; t}^{\text {Aging } 4}=\frac{t}{T} \times 100
$$

The allocation profile for all dynamic life-cycle strategies over the saving horizon could be visualized as follows. 
Figure 14 Equity Allocation of Dynamic Life-cycle Saving Strategies

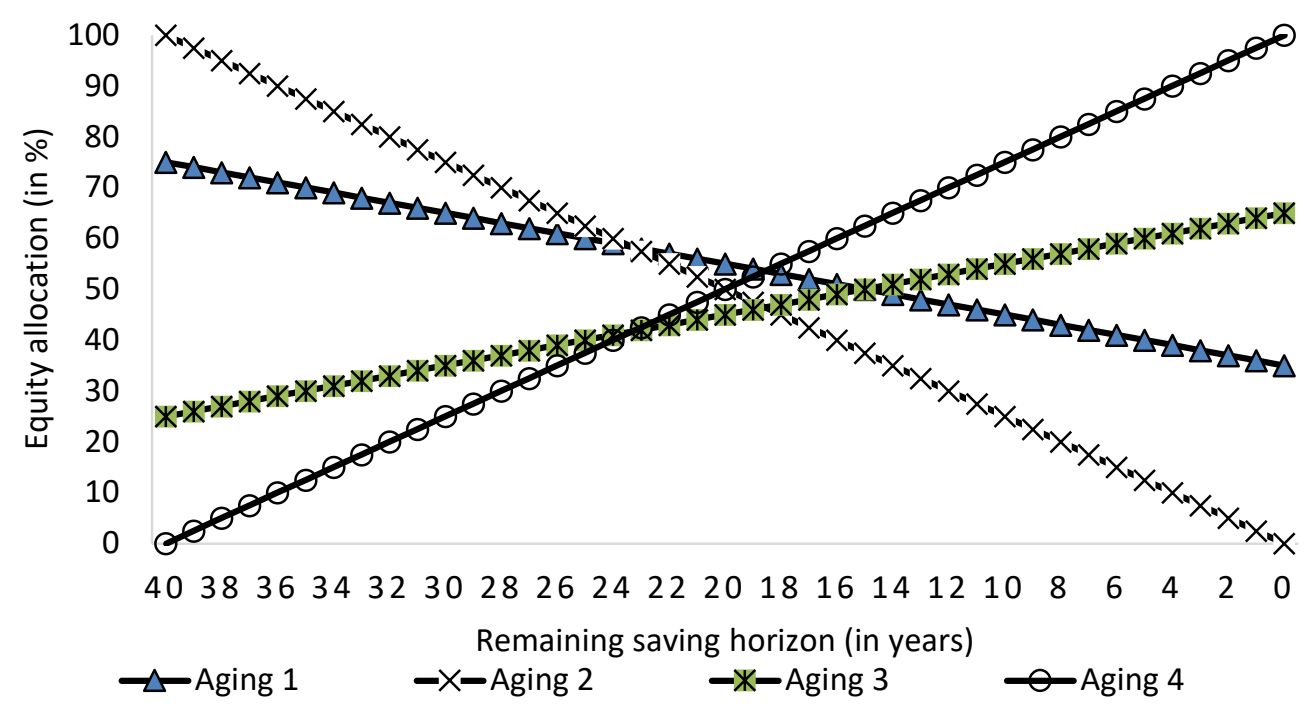

Source: Authors' own elaboration, 2019

The third group of saving strategies are quasi active ones, where the price movement of investments is considered. We have constructed three strategies, where the first one, "CrossEMA", only considers the price movements of underlying investments. The remaining two quasi active strategies (MaxMin, RiskTolerance) combine the price movement of the portfolio as well as the remaining saving horizon.

CrossEMA strategy is based on the simple approach of crossing moving averages. The principle of the strategy is based on a simple algorithm of crossing exponential moving averages (EMAs) of two underlying assets (ETFs):

$$
E M A_{t}(p)=P_{t} * \frac{2}{p+1}+E M A_{t-1}(p) *\left(1-\frac{2}{p+1}\right)
$$

Where:

$E M A$ - the value of the exponential moving average over the last $p$ days at time $t$;

$P_{t}$ - price of the underlying asset (ETFs) at time $t$;

$E M A_{t-1}$ - the value of the exponential moving average over the last $p$ days at time $t-1$.

In our case, the strategy decides whether to invest savings into the equity ETF based on the following rule:

$$
E M A_{t}\left(p_{S}\right)>E M A_{t}\left(p_{L}\right)
$$


Where:

$p$ is the number of trading days for which EMA is calculated;

$S$ and $L$ - short (S-short) and long ( $L$-long) periods defined by the number of days.

In our case, we consider $p_{S}=5$ days and $p_{L}=130$ days. The lengths of the periods were deliberately determined to coincide with a length of one week $\left(p_{S}\right)$ and about half a year $\left(p_{L}\right)$. For other moving average strategies, we also use other trading day parameter settings that are based on different approaches. Thus, in the literature, it often appears to set the length of the season by the number of trading days from 240 to 270, for the half-year period from 120 to 135 and the like. The setting of the number of trading days for the moving average calculation thus depends solely on the approach of a researcher. If condition (9) is met, strategy allocates $100 \%$ of savings $\left(w_{i s, t}\right)$ to the equity ETF, otherwise $0 \%$.

Another quasi-active strategy is the MaxMin strategy. The principle of this strategy is based on the game theory under the risk and uncertainty. The decision-making mechanism is based on the fact that an agent does not have the opportunity to obtain information about the probability of the price movement of the underlying asset for the future and therefore does not try to estimate the probability of expected return. However, they know past prices and assume that if the price exceeds the local maximum, it tends to rise. At the same time, this assumption also applies when the local minimum is exceeded downwards. If this happens, the price is expected to fall further. This determines the agent's behavior based on the effort to maximize the minimum profits that can be achieved and minimize the maximum losses that may occur over time. If the price of the equity ETF rises above its local maximum during the period under review, it tends to maintain the growth trend and continues to grow further in the short term. An agent uses this period to allocate savings to the risky asset (equity ETF). Otherwise, strategy allocates savings into the bond ETF. The MaxMin strategy determines the allocation ratio to a risky asset based on the proximity of the price to the local extreme (maximum or minimum) over the reference period. The strategy allocates $100 \%$ savings to the equity ETF if the following condition is met:

$$
\text { StopLoss }=0 \wedge B U Y=1
$$

The decision mechanism for the $B U Y$ signal is as follows:

$$
P_{S_{t}} \geq \max P_{S_{t, t-120}}
$$

Where:

$P$ is the price of the equity ETF at time $t ;$

maxP - maximum price of the equity ETF over the last 120 trading days.

$B U Y=1$ if the inequality in relation (11) is valid. The value of 120 has been chosen in accordance with the widespread use of this value in investment theory based on 
technical analysis of daily data using moving averages. However, other settings for this parameter can also be used. The decision-making mechanism of StopLoss is based on a comparison of the price $P$ of the equity ETF at time $t$ with the minimum EMA of the equity ETF over the last 133 trading days, while the price is multiplied by sensitivity $\left(\right.$ cit $\left._{t}\right)$. StopLoss $=0$ if the inequality in formula (12) is valid. The StopLoss decision algorithm has the form:

$$
P_{S_{t}} \leq \operatorname{minEM} A_{S_{t, t-133}} * c i t_{t}
$$

while

$$
E M A_{t}=\left[P_{t} * k+\min P_{t, t-133} *(1-k)\right] * c i t_{t}
$$

Where:

$\operatorname{minEMA}$ of equity ETF at the time $t$ is the lowest EMA during the period $\langle t-133$; $t\rangle$;

$P$ is the price of the equity ETF at time $t$;

$k$ - coefficient calculated as the ratio of number 2 and number of days of EMA calculation +1 ;

$\min P$ - minimum price of the equity ETF at time $t$ during the period $\langle t-133 ; t\rangle$.

The sensitivity $\left(\mathrm{cit}_{t}\right)$ expresses the rate of reaction of savings $\left(S_{a j, t}\right)$ at time $t$ exposed to investment risk to the total expected value of savings $\left(S_{a j, T}\right)$ at the end of savings period $T$. Sensitivity is based on the assumption that an agent reacts sensitively to negative deviation in the value of savings in the later savings phase. The greater the amount of savings accumulated, the higher the risk of loss in absolute terms than in the case of a similar situation at the beginning of a saving horizon with a lower accumulated amount of savings. Sortino (2010) introduced a negative deviation (Sortino ratio) when assessing the performance of fund managers against the Desired Target Return (DTR), trying to filter out that part of volatility that resulted in an increase in the price of financial assets. By sensitivity in this case we understand the function of time $t$ dependent on the total saving horizon $(T)$ expressed in days (months, years), if the decision algorithm is based on days (months, years). We denote the sensitivity at time $t$ as:

$$
\operatorname{cit}_{t}=\frac{t^{\frac{t}{T}}+t}{2 T}
$$

Where:

$t$ is the time period (day, month, year) from the start to the end of total saving horizon ( $\mathrm{T}$ );

$T$ - total saving period expressed in days (months, years). 
The course of the sensitivity curve more accurately captures the evolution of the savings, where future regular contributions are foreseen, as opposed to using a simple approach with an exponential function used in a one-off investment.

The third quasi-active saving strategy is called RiskTolerance and contains a key element of the savings-risk tolerance in its decision-making mechanism. Similarly, the RiskTolerance strategy is based on the comparison of the dynamic development of an underlying asset price over time. The RiskTolerance strategy is based on the following decision algorithm:

$$
w_{1 t}=\frac{\sum_{t-n}^{t} B U Y}{n}
$$

The term $\frac{\sum_{t-n}^{t} B U Y}{n}$ represents the average value of the $B U Y$ indicator over the last $n$ days (from $t-n$ to $t$ ), with $n$ being, for example, 22 days for a monthly frequency, about 66 days for a quarterly frequency, from 120 to 135 days for half-year frequency and 240 to 270 days for annual decision-making frequency. The BUY indicator at time $t$ could be as follows:

$$
B U Y_{t}=1-D R_{t}
$$

The term $D R_{t}$ represents the dynamic risk at certain point in time $t$ and is calculated as:

$$
D R_{t}=\left\{\begin{array}{l}
\frac{D_{\text {max }_{t}}-P_{s_{t}}}{D_{\text {max }_{t}}-D_{\text {min }_{t}}}, \text { if } D_{\text {max }_{t}} \neq D_{\text {min }_{t}} \\
0, \quad \text { if } D_{\text {max }_{t}}-D_{\text {min }_{t}}<0
\end{array}\right.
$$

Where:

$D_{\max }$ represents the maximum price $P_{s_{t}}$ of equity ETF at time $t$ within the interval $\langle k, t\rangle$;

$D_{\min }$ represents the minimum price $\left(P_{S_{t}}\right)$ of equity ETF at time $t$ within the interval $\langle k, t\rangle$, while $k=\max (1 ; 2 t-T)$.

The interval $\langle k, t\rangle$ for finding the local minimum and maximum in the first half of a saving horizon causes an increase in the preference for allocating savings into the riskier equity ETF. As the interval $\langle k, t\rangle$ gets shorter in the second half of a saving horizon, the strategy increases the preference for allocating savings into the bond ETF.

Usually, any strategy is assessed using several indicators. In our case, we have tried to simplify the approach and only focus on 2 indicators that should reflect the expected performance over the whole saving horizon and the short-term risk represented by the maximum expected draw-down of the savings during the saving horizon. 
The first indicator $\left(\operatorname{Per} f_{T}\right)$ compares the volume of accumulated savings $\left(S_{a j, T}\right)$ at the end of the saving horizon $T$ and the volume of contributions paid over the entire saving period $\left(\sum_{t=1}^{T} C_{t}\right)$. The savings performance indicator $\left(\operatorname{Per} f_{T}\right)$ is calculated as follows:

$$
\operatorname{Per} f_{T}=\frac{U_{T}}{C_{T}^{*}}-1
$$

The savings performance indicator $\left(\operatorname{Per} f_{T}\right)$ expresses the rate of appreciation of contributions made by a saver under the chosen savings strategy during the whole saving period. It represents an individual rate of appreciation of savings due to the existence of a saving strategy and an individualized lifetime income function.

Secondly, we try to assess what kind of investment risk a saver has to undergo in order to achieve above mentioned savings performance. In most cases, the investment risk is viewed as a short-term risk represented by volatility or VaR (value-at-risk), which in short is the $95^{\text {th }}$ percentile of all down-side movements. In our case, we want to be stricter and use the maximum draw-down $\left(\operatorname{Max} D D(\%)_{t}\right)$ an agent suffers during the saving horizon, represented by the $100^{\text {th }}$ percentile of all simulations. MaxDD can be calculated as follows:

$$
\operatorname{Max} D D(\%)_{t}=\operatorname{MIN}_{t}\left\{\frac{\left[U_{t}-\operatorname{MAX}\left(U_{\hat{t}}\right)\right]}{\operatorname{MAX}\left(U_{\hat{t}}\right)} \times 100, \operatorname{Max} D D(\%)_{\hat{t} *}\right\} ; \hat{t} \in\langle 1, t\rangle, t \in\langle 2, T\rangle
$$

Using the maximum draw-down as an indicator of a short-term risk allows us to consider the behavioral aspect of risk aversion. In other words, using the maximum draw-down indicates the maximum fall in the value of savings an agent has to suffer during the saving horizon. For an agent, this indicator is a good proxy of how much down-side risk he/she is willing to accept in order to achieve an expected return measured by savings performance at the end of the saving horizon.

\section{Research Results and Discussion}

We have performed more than 3,3 mil. simulations under the various economic conditions including unemployment rates, equity and bond returns. First, we present the correlation matrix, where tested dynamic life-cycle as well as quasi active strategies are compared to the static ones with border allocations conservative and aggressive strategies.

When inspecting the tested strategies, one can see that dynamic life-cycle strategies Aging1 and Aging 4 and quasi active saving strategy RiskTolerance are highly correlated with the aggressive saving strategy, where the contributions and the savings are invested solely into the equity ETF for the entire saving period. One can therefore expect that these two strategies will also deliver higher savings performance as well as higher down-side risks. 
Table 5 Correlation Matrix of Tested Saving Strategies Based on the Savings Performance

\begin{tabular}{|c|c|c|c|c|c|c|c|c|c|}
\hline & 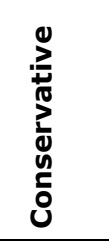 & 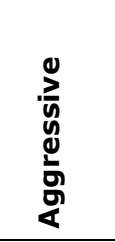 & $\begin{array}{l}\underset{X}{\mathbb{N}} \\
\sum_{\Sigma} \\
\frac{\Xi}{\Sigma}\end{array}$ & 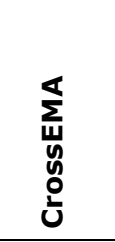 & 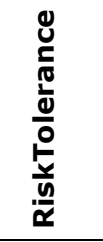 & 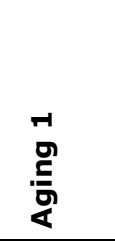 & $\begin{array}{l}\text { N } \\
\text { ס } \\
\text { 自 }\end{array}$ & 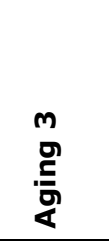 & 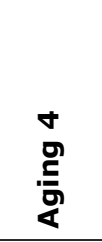 \\
\hline Conservative & 1.000 & & & & & & & & \\
\hline Aggressive & 0.213 & 1.000 & & & & & & & \\
\hline MinMax & 0.438 & 0.785 & 1.000 & & & & & & \\
\hline CrossEMA & 0.333 & 0.705 & 0.650 & 1.000 & & & & & \\
\hline RiskTolerance & 0.394 & 0.953 & 0.797 & 0.704 & 1.000 & & & & \\
\hline Aging 1 & 0.417 & 0.950 & 0.823 & 0.721 & 0.932 & 1.000 & & & \\
\hline Aging 2 & 0.461 & 0.895 & 0.796 & 0.713 & 0.890 & 0.973 & 1.000 & & \\
\hline Aging 3 & 0.618 & 0.850 & 0.813 & 0.676 & 0.879 & 0.926 & 0.863 & 1.000 & \\
\hline Aging 4 & 0.363 & 0.922 & 0.785 & 0.715 & 0.899 & 0.956 & 0.985 & 0.820 & 1.000 \\
\hline
\end{tabular}

Source: Authors' own elaboration, 2019

When considering the savings performance, we present not only the mean values but also standard deviations as well as key percentiles including the maximum and minimum of all simulations.

When inspecting the savings performance indicator, logically, the lower risk allocation strategies delivered the lowest performance (Conservative saving strategy and the static strategies investing low proportion of savings into the riskier assets). A little surprisingly, Aging1 and Aging2 strategies, which are admired by many researchers and policy-makers, did not deliver exceptional returns and could not beat even the static strategy that constantly invests $50 \%$ of the portfolio into the equity ETFs. On the other hand, the standard deviations of aging strategies are lower than the static ones. Quasi-active saving strategies delivered mixed results. The simple and often recommended active strategy based on the EMAs (CrosSEMA) has delivered lower than average results with a relatively high volatility. However, quasi-active strategies (MaxMin and RiskTolerance) that take into account the age of a saver (or the remaining saving horizon) delivered quite exceptional performance compared to the other life-cycle or static strategies. 
Table 6 Performance of Saving Strategies

\begin{tabular}{|c|c|c|c|c|c|c|c|c|c|}
\hline Strategy & 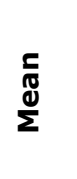 & نे & 竞 & 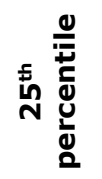 & î & 乩 & 站 & $\underset{\sum}{\stackrel{x}{\Sigma}}$ & $\frac{5}{\Sigma}$ \\
\hline Conservative & 97 & 36 & 52 & 69 & 91 & 118 & 167 & 239 & 27 \\
\hline Aggressive & 217 & 228 & -39 & 51 & 169 & 310 & 677 & 1784 & -79 \\
\hline $90: 10$ & 205 & 206 & -27 & 55 & 161 & 288 & 623 & 1621 & -64 \\
\hline $80: 20$ & 192 & 184 & -15 & 59 & 154 & 267 & 566 & 1458 & -49 \\
\hline 70:30 & 180 & 163 & -4 & 62 & 146 & 246 & 511 & 1295 & -37 \\
\hline 60:40 & 168 & 141 & 8 & 65 & 138 & 227 & 450 & 1132 & -26 \\
\hline 50:50 & 159 & 122 & 20 & 70 & 133 & 213 & 402 & 992 & -15 \\
\hline 40:60 & 147 & 101 & 30 & 73 & 126 & 193 & 345 & 825 & -4 \\
\hline $30: 70$ & 134 & 80 & 40 & 76 & 119 & 174 & 289 & 658 & 8 \\
\hline 20:80 & 122 & 61 & 47 & 76 & 110 & 156 & 233 & 491 & 19 \\
\hline $10: 90$ & 110 & 44 & 53 & 74 & 102 & 137 & 191 & 324 & 30 \\
\hline CrossemA & 140 & 113 & 8 & 63 & 115 & 189 & 343 & 1050 & -56 \\
\hline MaxMin & 217 & 182 & 16 & 92 & 175 & 284 & 572 & 1341 & -50 \\
\hline RiskTolerance & 188 & 161 & 20 & 81 & 146 & 247 & 510 & 1416 & -33 \\
\hline Aging 1 & 150 & 97 & 21 & 77 & 137 & 206 & 327 & 665 & -19 \\
\hline Aging 2 & 130 & 66 & 41 & 80 & 121 & 167 & 249 & 465 & 7 \\
\hline Aging 3 & 148 & 99 & 5 & 75 & 138 & 208 & 329 & 568 & -45 \\
\hline Aging 4 & 170 & 144 & -28 & 65 & 149 & 251 & 446 & 824 & -75 \\
\hline
\end{tabular}

Source: Authors' own elaboration, 2019

Considering both the average performance and the performance achieved at the $5^{\text {th }}$ percentile, the picture might look little differently.

One can see that static saving strategies delivered proportionally higher mean savings performance (vertical " $y$ " axis) and lower performance at $5^{\text {th }}$ percentile (horizontal " $x$ " axis) based on the proportion of savings invested into the riskier equity ETFs. The generally recommended Aging1 strategy delivered below average results both at the mean (cumulative return of $150 \%$ ) as well as at the $5^{\text {th }}$ percentile (cumulative return of $21 \%$ ) over a saving horizon of 40 years. The quasi-active strategy CrosSEMA delivered poor results as well. Other quasi-active strategies that take into account the risk tolerance and the remaining saving horizon (MaxMin and RiskTolerance) delivered above average performance both at the mean $(217 \%$, respectively $188 \%$ ) as well as at the $5^{\text {th }}$ percentile $(16 \%$, respectively $20 \%$ ). MaxMin strategy delivered almost the same mean performance as the Aggressive static strategy investing $100 \%$ of contributions exclusively into the equities $(217 \%)$ 
but at the same time it was still able to deliver at least $16 \%$ performance compared to the fully equity strategy that delivered only poor $-39 \%$ (lost $39 \%$ of the total number of contributions paid during the entire saving horizon) at the $5^{\text {th }}$ percentile.

Figure 15 Performance of Savings Strategies - Mean vs. 5th Percentile

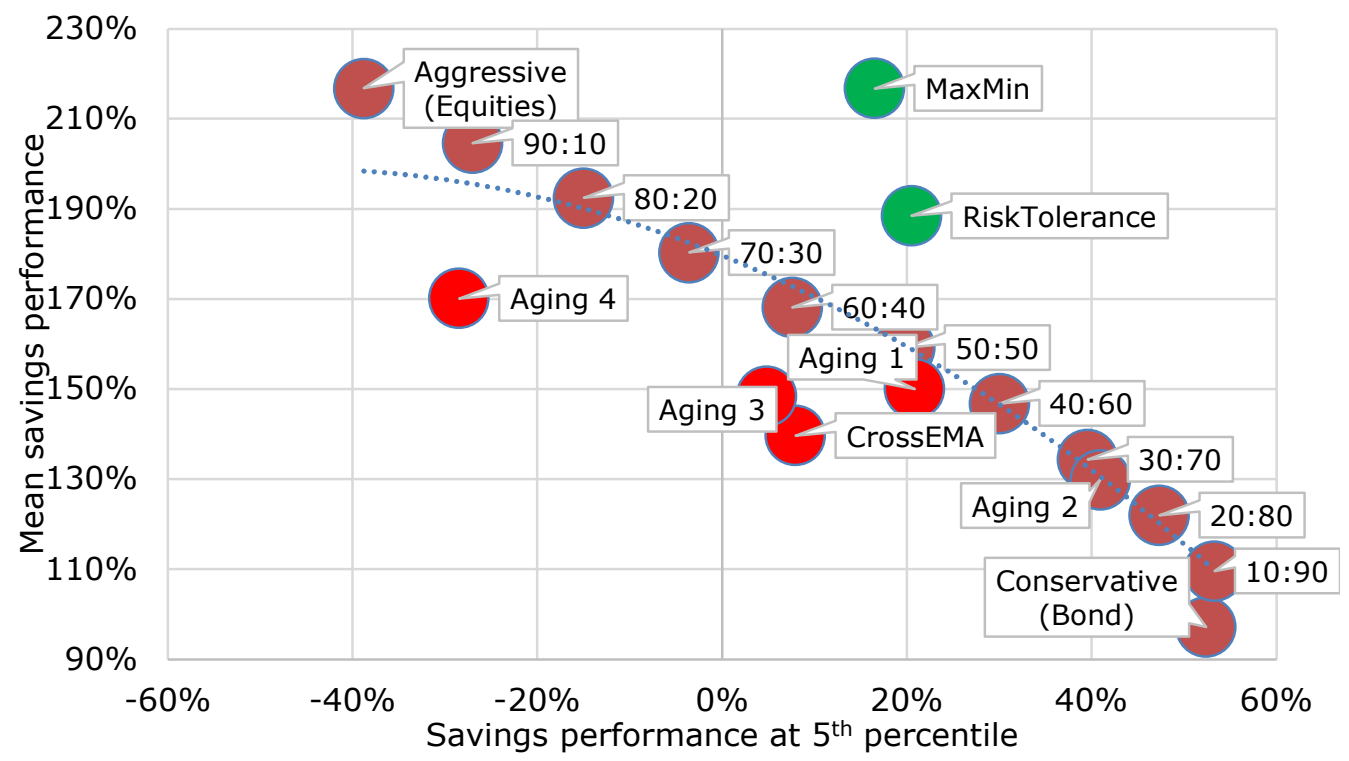

Source: Authors' own elaboration, 2019

Secondly, we present the mutual relationship of short-term and long-term risks using the indicators of maximum draw-down and mean savings performance. By doing so, we can easily examine the trade-off between the short- and long-term risk and assess both the expected down-side risk and expected returns. By mentioning the maximum draw-down indicator it should be clear that this is not the maximum draw-down one can experience at the end of the saving horizon but anytime during the saving horizon, and must survive it.

Logically, the full equity saving strategy (Aggressive) has the highest expected down-side risk (56\%) during the saving horizon as well as expected return $(217 \%)$ at the end of the saving horizon among all analyzed saving strategies. On the other hand, the Conservative strategy delivered expected mean return of $97 \%$ and the saver had to suffer the maximum draw-down of only $6 \%$. In order to achieve high performance in the long-term, one has to be prepared to suffer more on average. Surprisingly, all life-cycle saving strategies (Aging 1, Aging 2, Aging 3 and Aging 4) performed below average and delivered lower than average performance $(150 \%$, $130 \%, 148 \%$ and $170 \%)$ and higher short-term risks (31\%, 25\%, $28 \%$ and $40 \%$ ) compared to the static saving strategies. This leads us to the conclusion that a general application of saving strategies based on the factor of age would harm the saver and expose them to a higher adequacy risk as well as higher potential shortterm losses. The same applies to the quasi-active strategy (CrossEMA) that takes 
into account only the price movement of underlying assets. However, two quasiactive strategies that take into account the development of underlying asset prices as well as the remaining saving horizon (MaxMin and RiskTolerance) performed rather well, delivering both high performance and lower down-side risks during the accumulation phase compared to the static peers.

Figure 16 Maximum Draw-down and Performance of Saving Strategies

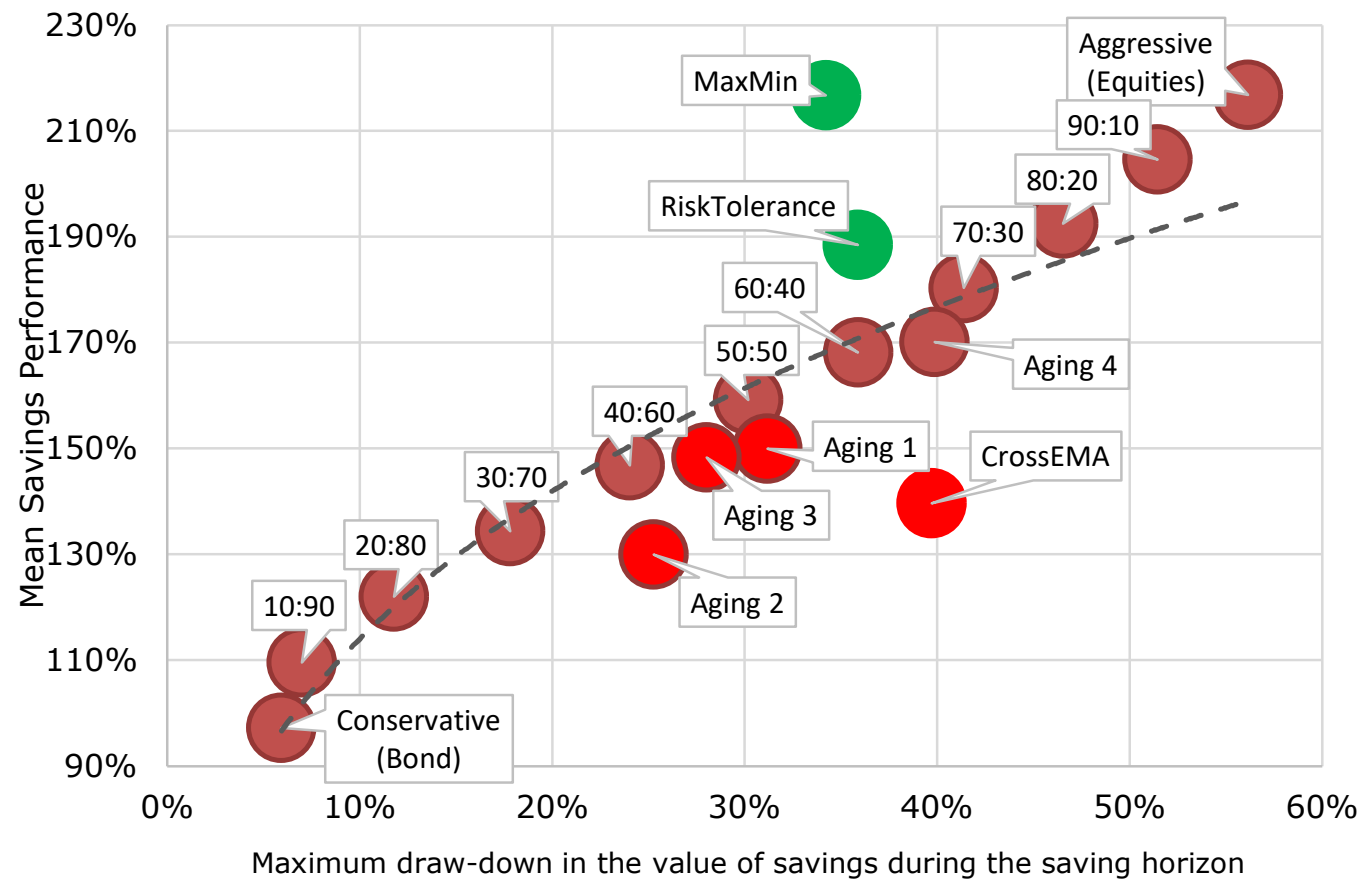

Source: Authors' own calculations, 2019

Considering the high correlation of quasi active saving strategies that take into account the price movement as well as remaining saving horizon with the aggressive strategy investing solely into the equities, we can claim, with caution, that the optimal saving strategy should take into account both factors - price movement as well as the remaining saving horizon. The benefit for this would be a lower overall down-side risk compared to the equity-based strategies and higher performance compared to the conservative peers.

\section{Conclusions}

This paper examines the efficiency of three most discussed groups of saving strategies - static, dynamic life-cycle, and quasi active ones. Overall, we tested 18 strategies using the novel moving-block bootstrapping method that allows to keep correlations among key macroeconomic parameters present. The efficiency of strategies was tested for the savings performance at various percentiles supplemented with the down-side risk during the saving horizon. Especially, the 
novel approach to measure the down-side risk during the saving process would allow us to inspect what level of temporary draw-down in the value of savings a respective agent would need to undertake and/or sustain.

The first conclusion from the research is that dynamic life-cycle saving strategies, which are generally admired for their superb risk-reward profile, did not prove to be the optimal choice for long-term investment saving process. Having the age or the remaining saving horizon as the only factor of portfolio allocation proved to be risky, both in terms of expected performance at the end of the saving horizon as well as the down-side risk during the saving process.

The second conclusion is that using the two-factor approach, where on top of the age / remaining saving horizon, the price movement is considered, could return interesting results from both sides - higher expected performance and lower downside risks during the saving process. However, a higher portion of equities during the entire accumulation phase is essential for achieving high performance. At the same time, the sensitivity of savings on the down-side risk should be measured, especially during the last third of the saving horizon.

\section{Acknowledgments}

The authors are thankful for the support of the Orange Envelope, the university spin-off research organization implementing the research results into the modern online platform providing Integrated Pension Benefit Statements and projections (www.oranzovaobalka.sk).

The work was supported by the Slovak Research and Development Agency under the contract No. APVV-19-0352.

\section{References}

Antolin, P., Payet, S. and Yermo, J. (2010). Assessing default investment strategies in defined contribution pension plan. OECD Journal: Financial Market Trends, 1, pp. 87-115.

Berardi, A., Tebaldi, C. and Trojani, F. (2018). Consumer Protection and the Design of the Default Option of a Pan-European Pension Product. Swiss Finance Institute Research Paper No. 19-19. Available at: http://dx.doi.org/10.2139/ssrn.3142243

Berstein S., Fuentes O. and Villatoro F. (2013). Default investment strategies in a defined contribution pension system: A pension risk model application for the Chilean case. Journal of Pension, Economics and Finance, 12(4), pp. 379-414.

EIOPA. (2020). Pan-European Personal Pension Product (PEPP): EIOPA's Stochastic Model for a Holistic Assessment of the Risk Profile and Potential Performance. EIOPA-20-505, 14 August 2020.

Fodor, J. and Cenker, J. (2019). Default strategy in pension saving. The case of Slovakia, Economics analysis 51. Institute for Financial Policy - Ministry of Finance of Slovak Republic. 
Kopa, M., Šutiené, K., Kabasinskas, A. and Meštan, M. (2019). Stochastic dominance analysis of Slovak 2nd pillar pension funds, Financial management of firms and financial institutions: 12th international scientific conference, ISSN 2336162X, pp. 112-121.

Manor, M. (2017). Efficient life cycle investment strategies in defined contribution pension plans in Israel. Journal of Insurance, Financial Markets and Consumer Protection, 26(4), pp. 47-66

Merton, R. C. (1971). Optimum consumption and portfolio rules in a continuoustime model. Journal of Economic Theory, 3.4, pp. 373-413.

NBER, 2019. US Business Cycle Expansions and Contractions. Available at: http://www.nber.org/cycles/cyclesmain.html

Poterba, J., Rauh, J., Venti, S. and Wise, D. (2006). Lifecycle asset allocation strategies and the distribution of $401(\mathrm{k})$ retirement wealth. NBER Research Paper w11974. Available at: https://www.nber.org/papers/w11974

Samuelson, P. A. (1969). Lifetime portfolio selection by dynamic stochastic programming. The review of economics and statistics, pp. $239-246$.

Šebo, J., Melicherčík, I., Mešt́an, M and Králik, I. (2017). Aktívna správa úspor v systéme starobného dôchodkového sporenia. Bratislava: Wolters Kluwer, 208 p. ISBN 978-80-8168-692-4.

Sortino, F. (2010). The Sortino Framework for Constructing Portfolios. ELSEVIER. ISBN 978-0-12-374992-5 